\title{
$\alpha$-Linolenic acid as a regulator of the metabolism of arachidonic acid: dietary implications of the ratio, n-6:n-3 fatty acids
}

By P. Budowski* and M. A. Crawfordt, Department of Nutritional Biochemistry, Nuffield Laboratories of Comparative Medicine, Institute of Zoology, London NW I $4 R Y$

The papers presented at this symposium have been concerned with membrane structure and function, in which dietary fatty acids (FA) are known to play a role. The subject of the present paper reflects one particular aspect of the relation between dietary polyunsaturated fatty acids (PUFA), membrane function and health.

The present debate on the role of dietary fats in cardiovascular disease and cancer has promoted national and international committees to make recommendations to the general public. The latest of these in the UK include the report of the National Advisory Council on Nutrition Education (NACNE, 1983) which presents general guidelines for the population, and the report on diet and cardiovascular disease by the Committee on Medical Aspects of Food Policy of the Department of Health and Social Security ( 1984$)$. These two reports are, in general, consistent with the principal themes from international committees (e.g. Food and Agriculture Organization/World Health Organization (FAO/WHO, 1978; WHO, 1982) and the recommendations made in the USA, Australia, Scandinavian countries, and elsewhere.

A common feature of these reports is the recommendation to reduce the intake of fats, particularly saturated fats; many also refer to the PUFA and the need to aim for a balance between PUFA and saturated FA, so as to achieve a polyunsaturated: saturated $(\mathrm{P}: \mathrm{S})$ ratio. in the region of $0 \cdot 6-\mathrm{r} \cdot \mathrm{O}(\mathrm{FAO} / \mathrm{WHO}, 1978$; NACNE, 1983). None of the reports, with the exception of FAO/WHO (1978), mentions the question of the two families of essential fatty acids (EFA): the linoleic (LA) and $\alpha$-linolenic acid $(\operatorname{LnA})$ families. The usual approach is to discuss the $P: S$ ratio, which in practice is often restricted to the ratio, LA:saturated FA.

Because all these recommendations are directly concerned with dietary fats, the question has been raised as to their implications for membrane function. Animal membrane lipids basically consist of cholesterol and phospholipid; the ratio, cholesterol:phospholipid is one of the determinants of membrane fluidity (Chapman, 1972). The contribution of the phosphoglycerides to the fluidity of the membrane will depend on the balance between the individual phosphoglycerides and on the nature of the acyl groups. The effect of dietary fats will be predominantly on the acyl groups. In the polar phosphoglycerides the I-position

-Present address: The Hebrew University of Jerusalem, Faculty of Agriculture, PO Box I2, Rehovot 76 I00, Israel.

$\dagger$ For reprints. 
usually contains a saturated or mono-unsaturated FA, whilst the 2-position holds a PUFA. Only in highly specialized membranes is a PUFA found in the I-position or a saturated FA in the 2-position. This means that there is an upper limit on the amount of PUFA that will be held in membrane phosphoglycerides. Because of competition for the 2-position, dietary PUFA will be incorporated into membrane lipids on the basis of the degree of preference of the acyl-transferases for the different PUFA and the efficiency of the conversion of the parent PUFA to the long-chain derivatives. Therefore the dietary balance between the n-6 and n-3 FA is a determinant of membrane FA composition.

\section{Essential fatty acids}

Among the dietary PUFA, LA and LnA are by far the most abundant. When the concept of EFA arose, a little over $5^{\circ}$ years ago (Burr \& Burr, 1930), both LA and $\operatorname{Ln} A$ were thought to be essential for the rat. Later, it was found that $\operatorname{Ln} A$ was less than $10 \%$ as effective as LA in the rat-growth test under conditions of restricted water intake (Thomasson, 1953). This, and the lesser abundance of $\operatorname{LnA}$ in western diets, caused research on $\operatorname{Ln} A$ to be somewhat neglected over the years, the focus of interest being mainly on LA. Yet Sinclair (1959) vigorously argued in favour of a distinct role for LnA, and Bernsohn \& Stephanides (1967), on the basis of the geographical distribution of incidence of multiple sclerosis, suggested that the disease was linked to a low intake of $\operatorname{LnA}$ or its metabolic derivatives (n-3 FA). $A$ revival of interest in the $n-3 F A$ arose only recently, when earlier studies of Eskimos and their marine diet by Sinclair (1953) and Bang et al. (1971) culminated in the suggestion by Dyerberg et al. (1978) that icosapentaenoic acid (IPA), a derivative of $\operatorname{LnA}$ found in fish and marine mammals, might have antithrombotic activity. The announcement set in motion intense research activities, starting with the confirmation of the antiaggregating effects of marine lipids in man (Siess et al. 1980; Sinclair, 198I) and resulting in a large number of reports covering diverse aspects of the biological effects of IPA and fish oils (e.g. Durie, 1984).

The important effects of the PUFA of fish lipids raise the question of the significance of the precursor FA, LnA, in the human diet. $\mathrm{LnA}$ is a major PUFA, second only to LA in western diets. Both FA can only be synthesized in the vegetable kingdom, but animals are able to desaturate and elongate these two $F A$, thus giving rise to two distinct PUFA families: the n-6 PUFA, derived from LA, and the n-3 FA whose precursor is LnA. No interconversion between these two families of FA is possible in the animal organism. The $\mathrm{C}_{20}$ and $\mathrm{C}_{22} \mathrm{FA}$ are characteristic constituents of animal membrane lipids, and some of them are substrates for the biosynthesis of a complex series of potent cell regulators collectively referred to as icosanoids, which include the prostaglandins (PG), thromboxanes (TX) and leukotrienes (LT). The long-chain PUFA and icosanoids formed from them are thus ultimately derived from LA and LnA. The conversion of the FA to their long-chain metabolites can occur at various stages of the food chain. Certain carnivores have lost the capacity for conversion and receive their 
long-chain PUFA from their prey (Rivers et al. 1975), while omnivores eat both parent and derived PUFA, and herbivores principally the precursor FA.

The essentiality of LA in many animal species has been abundantly documented (Holman, 1968), and normal growth and reproduction can be sustained by LA alone over several generations, both in rats (Tinoco et al. 1978) and guinea-pigs (Leat \& Northrop, I98I). LnA and derived n-3 FA have been shown to be essential for trout (Sinnhuber et al. 1972). Other species of fish also require n-3 FA, e.g. turbot, carp, red sea bream and the shellfish prawn (for review, see Opstvedt, 1984). However, only a handful of reports hinting at a requirement for $\operatorname{LnA}$ in warm-blooded animals has been listed (Budowski, 1984). For instance, Fiennes et al. (1973) reported alopecia, fatty liver and skin pathology in Capuchin monkeys fed on sunflower-seed oil as the only source of dietary fat for 18 months. This oil has a ratio, n-6:n-3 FA of about 50:1. When linseed oil, a rich source of $\operatorname{Ln} A$, was substituted for maize oil, the $n-6: n-3$ value in the erythrocyte phosphoglycerides was reduced and the pathological symptoms were reversed. Lamptey \& Walker (1976) reported that when rats were fed on a diet supplying only LA, the young of the second generation showed impaired learning ability compared with rats also receiving $\operatorname{Ln} A$ in the diet; growth and reproduction were normal, although there was substantial replacement of n-3 FA by n-6 FA in the phosphoglycerides, as also reported by Tinoco et al. (1978). LnA also seems to be needed for normal electroretinographic response in rats (Wheeler et al. 1975) and visual acuity in the rhesus monkey (Neuringer et al. 1984). A young patient receiving an intravenous infusion of an oil emulsion rich in LA but with only traces of LnA developed neurological disturbances that disappeared after the oil was replaced by one with a LA:LnA value of about 6:1 (Holman et al. 1982). These and a few additional reports provide the sparse evidence pointing to the essentiality of LnA in higher animals, in sharp contrast to the wealth of information concerning LA requirements. The high concentrations of docosahexaenoic acid, a derivative of LnA, in brain grey matter, retina and other tissues (for review, see Tinoco et al. 1979) may be taken as circumstantial evidence that $n-3 \mathrm{FA}$ are required by certain specialized cell structures.

\section{'Unrestrained' arachidonic acid metabolism and the regulatory effect of $L n A$}

The possibility that LnA might function in a way which radically differs from the EFA role of LA has been suggested (Budowski, 198r, 1984). Briefly, $\operatorname{LnA}$ is viewed as a regulator of the metabolism of $L A$ and arachidonic acid $(\operatorname{ArA})$. There are several ways in which $\operatorname{LnA}$ may modulate ArA metabolism, the best known of which are: (a) competitive inhibition by LnA of the conversion of LA to ArA (Mohrhauer \& Holman, 1953), resulting in decreased amounts of substrate available for PG and TX production; (b) conversion of LnA to IPA, which is an effective inhibitor of cyclo-oxygenase (Needleman et al. 1979), hence a reduction in the yield of the major PG and TX formed from the available ArA; and (c) formation of the strongly antiaggregating $\mathrm{PGI}_{3}$ from IPA, although there is evidence that the amounts of $\mathrm{PGI}_{3}$ metabolites appearing in human urine are very 
small, even after ingestion of large amounts of IPA from fish lipids (Fischer \& Weber, 1984).

That excessive production of TX from ArA can have detrimental consequences has been observed repeatedly. Intravenous $\operatorname{Ar} A$ as the sodium salt caused pulmonary platelet aggregation and sudden death in rabbits (Silver et al. 1974), as well as stroke in rats (Furlow \& Bass, 1975). Ingestion of ethyl arachidonate led to enhanced platelet aggregability in humans (Seyberth et al. 1975). Chick nutritional encephalomalacia (NE) may be another example of excessive TX production with a fatal outcome caused by unrestrained ArA metabolism (Budowski et al. 1980). The cerebellar lesion can only be induced by diets deficient in vitamin $E$ and containing a source of LA (Dam et al. 1958) or ArA (Dam \& Sondergaard, r962), the latter FA being the most effective. The disease is accompanied by thrombus formation in the small blood vessels of the cerebellum and by a shortening of bleeding time (Budowski et al. 1980). According to Higgs et al. (1981), human diseases with a tendency toward thrombotic complications exhibit a disturbed balance in TX and prostacyclin production, with a shift toward excessive thromboxane synthesis, but this idea is not universally accepted: for instance, in rats, fish-oil feeding reduced both platelet TXA2 and vascular PGIz production, even though arterial thrombosis was depressed and bleeding time was prolonged (Hornstra et al. I981).

Evidence that the restraining action of $\operatorname{LnA}$ on ArA metabolism can have beneficial effects is also available. $\operatorname{LnA}$ not only fails to induce NE (Dam et al. I958), but also exerts a protective effect against the cerebellar lesion (Budowski et al. 1980). Preliminary results (E. Vericel, unpublished results) indicate that the protective action of $\operatorname{LnA}$ in chick $\mathrm{NE}$ may be related to the greatly decreased thrombocyte aggregability, reduced $\mathrm{TXB} 2$ production by collagen-stimulated thrombocytes, and decreased arterial synthesis of PGE2. In rats previously made hypercholesterolaemic by a diet rich in saturated fat and cholesterol, venous thrombosis and platelet stickiness were corrected by a supplement of linseed oil, while maize oil exacerbated the condition (Nordoy, $1965 a, b$ ). When thrombus formation was induced in rats fed on saturated fat by intravenous injection of a low dose of ADP, the inclusion of linseed oil in the diet caused a greater reduction in thrombosis than did cottonseed oil (Nordoy et al. 1968). Linseed oil was also more effective than maize oil in reducing platelet aggregability in rabbits (Vas Dias et al. 1982). Others (Hwang \& Carroll, 1980; Hansen et al. 1983) reported that the administration of purified esters of LnA reduced PG production in rats, and linseed oil feeding resulted in a similar effect in rats and rabbits (ten Hoor et al. 1980; Hornstra et al. 1983). An early controlled trial in which the effects of linseed and sunflower-seed oils on the incidence of coronary heart disease in Norway were compared failed to reveal any favourable effect of linseed oil (Natvig et al. 1968), but recent trials with volunteers showed that PG production was depressed linearly with increasing intakes of linseed oil (Adam et al. 1984), and measurements in two subjects indicated decreased platelet aggregability after ingestion of linseed oil (Budowski et al. 1984).

Of particular interest are the results obtained in a group of French farmers who 
replaced butter by low-erucic acid rapeseed oil and rapeseed-oil-rich margarine over a period of 1 year (Renaud et al. 1980). The only significant change in PUFA intake was an increase in LnA from 1.24 to $3.6 \%$ of the total dietary FA. The LA content of the diet remained constant at $17 \%$. Although the IPA level of plasma and platelets increased significantly, it remained below $0.6 \%$ of the total FA, while platelet ArA fell slightly, from 29.1 to $26.8 \%$. There were, however, marked alterations in platelet aggregability and platelet coagulant activity. In discussing these results, Renaud $\&$ Nordoy ( 1983 ) concluded that 'minor changes in dietary lipids with moderate changes in tissue FA composition in man may be most significant in the context of thrombosis prevention'.

\section{$P G$ production and membrane $F A$ composition}

The question of why platelet function can be altered without substantial changes in platelet membrane FA composition is intriguing. A clue to the answer to this question may be found in the results of an EFA-depletion study in rabbits. Unlike the rat, in which $n-3$ FA are tenaceously retained during EFA depletion, the rabbit tends to maintain its n-6 FA (as a model for EFA-deficiency studies, the rat, from which most of our values are derived, seems to be of limited applicability). Studies by Hassam et al. (1979) and Willis et al. (1981) showed that when rabbits were fed on an EFA-deficient diet, the concentration of ArA in the major membrane phospholipids initally increased (thus maintaining membrane unsaturation and fluidity). Nevertheless, endogenous production of PGE1, PGE2 and PGF $2 a$ fell dramatically in brain, skin, aorta, lung and liver. These results imply that membrane ArA is not always a precursor for endogenous PG production. It was therefore suggested (Crawford, 1983) that there are two pools of PG precursor: (1) a pool fed by dietary LA or by LA and ArA mobilized from metabolic reserves (neutral lipid) and responsible for cell regulation and homeostasis; (2) a membrane-bound pool which would provide the PG precursor as the result of biochemical stimulation or mechanical trauma, e.g. release of ADP or exposure to collagen as a response to cell injury. The idea of mechanical effects on PG production was already discussed by Piper \& Vane (1971). Kuhn (1983) recently investigated $P G$ production in perfused human placenta, one of the tissues whose phosphoglycerides are richest in ArA; PG synthesis, which was slow in the resting tissue, was substantially increased by squeezing the placenta with waves of air pressure. The physiological implications that this response may have for parturition are interesting. Similarly, Manabe et al. (1983) found that stretching of the uterus induced uterine contractions which were suppressed by administration of indomethacin and therefore presumably mediated by PG. Lagarde et al. (1981) reported that resting platelets synthesize more PGE I than PGE2, although the platelet membrane has much more ArA than dihomo- $\gamma$-linolenic acid, the precursors of $\mathrm{PGE}_{2}$ and $\mathrm{PGE}_{1}$ respectively; stimulation of the platelets with collagen or ADP resulted in more PGE2 being produced than PGEI, consistent with the involvement of a membrane-bound PG precursor pool. Also, the relative amounts of TX and PGr released from human umbilical vein were different in the 
perfused vein and in incubated venous rings (Mehta et al. 1982). Finally, measurements in vivo, e.g. of urinary PG metabolites in rats and humans (Hansen \& Jensen, 1983; Hornstra, 1985 ), have shown that PG production does not always correlate with tissue FA composition. Thus, it is clear that changes in PUFA intake can have a strong impact on PG production under both physiological and pathological circumstances, without necessarily altering membrane FA composition.

\section{Effects of dietary $L n A$ v. long-chain n-3 derivatives}

$\mathrm{LnA}$ is not equivalent in its biological effects to the long-chain n-3 FA found in marine oils. The latter are more rapidly incorporated into plasma and membrane lipids and produce more rapid effects, compared with LnA (Sinclair \& Crawford, 1972; Sinclair, I975; FAO/WHO, I978; Dyerberg et al. 1980, Sanders \& Younger, I $98 \mathrm{r}$; Sanders \& Roshanai, I $^{8} 33$ ). Relatively large reserves of LA in body fat, as are found in vegans, would tend to slow down the formation of long-chain n-3 FA from LnA (Sanders \& Naismith, 1980). Therefore, the role of LnA in human nutrition should be regarded from the point of view of long-term dietary habits. There are also some advantages in the consumption of $\operatorname{LnA}$ over n-3 FA from fish oils; problems such as insufficient vitamin $E$ intake, and excessive supply of vitamins $A$ and $D$, are not expected to arise from an increased intake of $\operatorname{Ln} A$ from plant sources.

\section{The significance of the dietary $L A: \operatorname{LnA}$ value}

If $\mathrm{LnA}$, and its $\mathrm{n}-3$ derivatives, have their place in the human diet as modulators of ArA metabolism and platelet function, the question arises as to the desireable level of supply for optimal membrane conditions. Because of the wide range of species differences, animal models do not provide an unambiguous answer to this question. Since direct evidence is not available, some information might be obtained from circumstantial evidence.

Because LA and LnA will compete for desaturation and incorporation, the relative amounts of $\operatorname{LnA}$ and $L A$ are important, rather than the absolute intake of $\operatorname{Ln} A$. The ratio, LA:LnA, calculated from food balance sheets, is now roughly 10:I in the UK (Taylor et al. 1979), and similar values are presumably found in other western countries. Actual analysis seems to yield a higher ratio, e.g. 14:1 in a French farming community (Renaud et al. 1980). The present preponderance of $\mathrm{n}-6$ FA over the n-3 FA may be traced to the steady increase in the production and consumption of LA-rich vegetable oils since the turn of the century, due to important technological innovations in the extraction and processing of vegetable oils and agrotechnical advances in the selection and cultivation of oil-seed plants (Budowski, 1984).

It is instructive to look at wild plants and animals which provided the food for prehistoric man. Such foods are not only mostly low in fat, but their lipids are also rich in PUFA (Crawford \& Stevens, 1981). Moreover, the ratio, LA:LnA (or $n-6: n-3 F A$ ) is, on the whole, fairly well balanced; LnA predominates in the 
chloroplasts of green, leafy plants, while seeds are as a rule richer in LA (Hitchcock \& Nichols, 1971). Muscle phospholipids of wild animals exhibit $n-6: n-3$ FA values ranging from 2:I to 4:I (Crawford et al. 1969, 1970a,b; Crawford \& Woodford, 1971). An analytical survey of thirty-two wild animal species in Africa yielded average ratios of $\mathrm{I}: \mathrm{I}$ in brain ethanolamine phosphoglycerides (EPG), the major phospholipid receptacle for PUFA in brain grey matter, and $1.6: 1$ in liver (Crawford et al. 1976). These findings show that, in spite of widely-varying patterns of food selection, animals tend to incorporate both types of PUFA into their membranes, in proportions ranging from $\mathrm{I}: \mathrm{I}$ to $5: \mathrm{I}$.

Human milk contains both n-6 and n-3 PUFA. A survey of over 2000 samples from 250 nursing mothers from Hungary and Thailand over a 6-month period (unpublished results) yielded a mean $n-6: n-3$ value of $4 \cdot 8$. Although the dietary habits and the total fat content of the breast milk were very different in the two countries, the above ratio was similar.

The evidence available from wild plants and animals which might have served as food for evolving Man, as well as the FA composition of mothers' milk, all seem to point to an $n-6: n-3$ value of less than 5 as a 'natural' (and therefore desirable) dietary PUFA ratio. This is well below what is found at present in western industrialized countries.

Only 150 generations have passed since man emerged from the mesolithic era. It is therefore reasonable to assume that, biologically, man is still a wild animal. At a recent international conference on 'Nutritional Adaptation in Man' (Blaxter \& Waterlow, 1985), it was concluded that there was little evidence of significant evolutionary adaptation to the contemporary extremes of either nutritional deprivation or excess. The comparison of 'wild' and contemporary foods leaves little doubt that there have been dramatic changes in what Man eats, and in northern Europe and America the most striking changes are of recent origin.

It should be noted that the national and international recommendations on the prevention of nutrition-related diseases are in agreement on the need to reduce the intake of fat, particularly saturated fat. If these recommendations are implemented, then a reduction in the level of total dietary fat must automatically redress to some extent not only the ratio, EFA:non-essential fatty acids but also the dietary n-6:n-3 balance, as the two PUFA families are fairly evenly represented in the structural lipids of plants and animals. Increasing the consumption of fish at the expense of meat would also contribute to a more balanced PUFA intake. Cell membranes would then acquire a PUFA composition closer to what might be considered as 'natural'.

If $\operatorname{LnA}$ and its derived n-3 FA are required for the regulation of $\operatorname{ArA}$, as well as for specialized cell structures, then the question of the dietary LA:LnA or $n-6: n-3$ values may be just as important, nutritionally, as the $P: S$ ratio.

\section{REFERENCES}

Adam, O., Wolfram, G., Reiter, S. \& Zollner, N. (1984). Fette, Seifen, Anstrichmittel 86, 181-189. Bang, H. O., Dyerberg, J. \& Nielsen, A. B. (1971). Lancet i, I143-1146. 
Bernsohn, J. \& Stephanides, L. M. (1967). Nature 215, 821-823.

Blaxter, K. L. \& Waterlow, J. C. (editors) (1985). Rank Prize Fund Symposium: Nutritional Adaptation in Man. Foumal of Human Nutrition, London: John Libby.

Budowski, P. (1981). Israel Fournal of Medical Sciences 17, 223-231.

Budowski, P. (1984). In International Conference on Diet and Nutrition, Tel-Aviv, February 1983. [C. Horwitz, editor]. London: John Libbey \& Co.

Budowski, P., Hawkey, C. M. \& Crawford, M. A. (1980). Annales de lo Nutrition et de l'Alimentation 34, 389-400.

Budowski, P., Trostler, N., Lupo, M., Vaisman, N. \& Eldor, A. (1984). Nutrition Research 4, $343-346$.

Burr, G. O. \& Burr, M. M. (1930). Fournal of Biological Chemistry 86, 587-621.

Chapman, D. (1972). In Lipids, Malnutrition and the Developing Brain, pp. $31-50$ [K. Elliot and J. Knight, editors]. Amsterdam: Associated Scientific Publishers.

Crawford, M. A. (1983). British Medical Bulletin 39, 2 10-213.

Crawford, M. A., Casperd, N. M. \& Sinclair, A. J. (1976). Fournal of Comparative Biochemistry and Physiology 54B, 395-401.

Crawford, M. A., Gale, M. M. \& Woodford, M. H. (1969). Biochemical fournal 11 5, 25-27.

Crawford, M. A., Gale, M. M. \& Woodford, M. H. (1970a). International Foumal of Biochemistry $1,654-658$.

Crawford, M. A., Gale, M. M., Woodford, M. H. \& Casperd, N. M (1970b). International fournal of Biochemistry I, 295-305.

Crawford, M. A. \& Stevens, P. A. (1981). In New Trends in Nutrition, Lipid Research and Cardiovascular Diseases, pp. 21 7-228 [N. G. Bazán, R. Paoletti and J. M. Iacono, editors]. New York: Alan R. Liss Inc.

Crawford, M. A. \& Woodford, M. H. (1971). International Fournal of Biochemistry 2, 493-496.

Dam, H., Nielsen, G. K., Prange, I. \& Sondergaard, E. (1958). Nature 182, 802-803.

Dam, H. \& Sondergaard, E. (1962). Zeitschrift für Ernährungswissenschaft 2, 21 7-222.

Department of Health and Social Security (1984). Committee on Medical Aspects of Food Policy, Diet and Cardiovascular Disease. Report no. 28. London: H.M. Stationery Office.

Durie, B. (editor) (1984). 2nd MaxEPA Conference. Symposium Supplement no. 31, British Journal of Clinical Practice 38, (5).

Dyerberg, J., Bang, H. O. \& Aagaard, O. (1980). Lancet i, I 99.

Dyerberg J., Bang, H. O., Stoffersen, E., Moncada, S. \& Vane, J. R. (1978). Lancet ii, II 7 .

Fiennes, R. N. T. W., Sinclair, A. J. \& Crawford, M. A. (1973). Fournal of Medical Primatology 2, $155^{-169 .}$

Fischer, S. \& Weber, P. C. (1984). Nature 307, $165-168$.

Food and Agriculture Organization/World Health Organization (1978). Fats and Oils in Human Nutrition. Rome: FAO.

Furlow, T. \& Bass, N. (1975). Science 187,658 .

Hansen, H. S., Fjalland, B. \& Jensen, B. (1983). Lipids $18,691-695$.

Hansen, H. S. \& Jensen B. (1983). Lipids 18, 682-690.

Hassam, A. G., Willis, A. L., Denton, J. P., Stevens, P. A. \& Crawford, M. A. (1979). Lipids 14, $78-80$.

Higgs, E. A., Moncada, S. \& Vane, J. P. (1981). In Prostaglandins, Platelets, Lipids, pp. 1-202 [H. L. Conn, Jr, E. de Felice and P. T. Kuo, editors]. New York: Elsevier.

Hitchcock, C. \& Nichols, B. W. (1971). Plant Lipid Biochemistry. London: Academic Press.

Holman, R. T. (1 g68). In Progress in the Chemistry of Fats and Other Lipids, vol. 9, pp. 274-348 [R. T. Holman, editor]. Oxford: Pergamon Press.

Holman, R. T., Johnson, S. B. \& Hatch, T. F. (1982). American Yournal of Clinical Nutrition 25, $617-623$.

Hornstra, G. (1985). International Conference on n-3 Fatty Acids, Reading, I6-18 July 1984.

Hornstra, G., Christ-Hazelhof, E., Haddeman, E., ten Hoor, F. \& Nugteren, D. H. (1981). Prostaglandins 21, 727-738.

Hornstra, G., Haddeman, E., Kloeze, J. \& Verschuren, P. M. (1983). Prostaglandin, Thromoxane and Leukotriene Research 12, 192-202.

Hwang, D. H. \& Carroll, A. E. (1980). American fournal of Clinical Nutrition 33, 590-597.

Kuhn, D. C. (1983). The transport and metabolism of essential fatty acids by the human placenta. PhD Thesis, Royal Free Hospital School of Medicine, London. 
Lagarde, M., Guichardant, M. \& Dechavanne, M. (1981). In Progress in Lipid Research, vol. 20, pp. 439-443 [R. T. Holman, editor]. Oxford: Pergamon Press.

Lamptey, M. S. \& Walker, B. L. (1976). Fournal of Nutrition 106, 86-93.

Leat, W. M. F. \& Northrop, C. A. (1981). Quarterly fournal of Experimental Physiology 66, 99-103.

Manabe, Y., Manabe, A. \& Takahashi, A. ( 1983 ). Prostaglandins 25, 653-659.

Mehta, P., Mehta, J., Crews, F., Roy, L., Ostrowski, N. \& Horalek, C. (1982). Prostaglandins 24, $743-749$.

Mohrhauer, H. \& Holman, R. T. (1963). Fournal of Nutrition 81, 67-74.

National Advisory Council on Nutrition Education (1983). Proposals for Nutritional Guidelines for Health Education in Britain. London: Health Education Council.

Natvig, H., Borchgrevink, C. F., Dedichen, J., Owren, P. A., Schiotz, E. H. \& Westlund, K. (1968). Scandinavian Yournal of Clinical Laboratory Investigations 2, Suppl. I05.

Needleman, P., Raz, A., Minkes, M. S., Ferrendelli, J. A. \& Sprecher, H. (1979). Proceedings of the National Academy of Sciences, USA 76, 944-948.

Neuringer, N., Connor, W. E., Van Petten, C. \& Barstad, L. (1984). Fournal of Clinical Investigations $73,272-276$.

Nordoy, A. (1965a). Thrombosis et Diathesis Haemorrhagica 13, 244-256.

Nordoy, A. ( $\left.1_{96} b\right)$. Thrombosis et Diathesis Haemorrhagica 13, 543-549.

Nordoy, A., Hamlin, J. T., Chandler, A. B. \& Newland, H. (1968). Scandinavian Yournal of Haematology $5,45^{8-473}$.

Opstvedt, J. (I984). In Fats in Animal Nutrition, pp. 53-82 [J. Wiseman, editor]. London: Butterworths.

Piper, P. \& Vane, J. R. (197r). Annals of the New York Academy of Sciences $180,363-385$.

Renaud, S., Dumont, E., Godsey, F., Morazain, R., Thevenon, C. \& Ortchanian, E. (1980). Nutrition and Metabolism 24, 90-104.

Renaud, S. \& Nordoy, A. (1983). Lancet i, I 169 .

Rivers, J. P. V., Sinclair, A. J. \& Crawford, M. A. (1975). Nature 285, 171.

Sanders, T. A. B. \& Naismith, D. J. (1980). Lancet i, $654-655$.

Sanders, T. A. B. \& Roshanai, F. (1983). Clinical Science 64, $91-99$.

Sanders, T. A. B. \& Younger, K. M. (1981). British Yournal of Nutrition 45, 61 $3-616$.

Seyberth, M. D., Oelz, O., Kennedy, T., Sweetman, B. J., Frolich, J. C., Heimberg, M. \& Oates, J. A. (I975). Clinical Pharmacology and Therapeutics 18, $52 \mathrm{I}$.

Siess, W., Scherer, B., Bohlig, B., Roth, O., Kurzmann, I. \& Weber, P. C. (1980). Lancet i, $44^{1-444}$.

Silver, M. J., Hoch, W., Kocsis, J. J., Ingerman, C. M. \& Smith, J. B. (1974). Science 183, 1085.

Sinclair, A. J. (1975). Lipids 10, 175-184.

Sinclair, A. J. \& Crawford, M. A. (1972). FEBS Letters 26, 1 $27-129$.

Sinclair, H. M. (1953). Proceedings of the Nutrition Society 2, 69-82.

Sinclair, H. M. (1959). Lancet i, 252-254.

Sinclair, H. M. (1981). In Progress in Lipid Research, vol. 20, pp. 897-899 [R. T. Holman, editor]. Oxford: Pergamon Press.

Sinnhuber, R. O., Castell, J. D. \& Lee, D. J. (1972). Federation Proceedings 31, 1436-1444.

Taylor, T. G., Gibney, M. J. \& Morgan, J. B. (1979). Lancet ii, 1378.

ten Hoor, F., de Deckere, E. A. M., Haddeman, E., Hornstra, G. \& Quadt, J. F. A. (1980). In Advances in Prostaglandin and Thromboxane Research, vol. 8, pp. $177 \mathrm{I}^{-1} 7^{81} \mathrm{I}$ [B. Samuelson, P. W. Ramwell and R. Paoletti, editors]. New York: Raven Press.

Thomasson, H. J. (1953). Internationale Zeitschrift für Vitaminforschung 25, 26-28.

Tinoco, J., Babcock, R., Hincenbergs, I., Medwadowski, B. \& Miljanich, P. (1978). Lipids 13, 6-17.

Tinoco, J., Babcock, R., Hincenbergs, I., Medwadowski, B., Miljanich, P. \& Williams, M. A. (1979). Lipids 14, 166-1 73 .

Vas Dias, F. M., Gibney, M. J. \& Taylor, T. G. (1982). Atherosclerosis 43, 245-257.

Wheeler, T. G., Benolken, R. M. \& Anderson, R. E. (1975). Science 188, 1312-1314.

Willis, A. L., Hassam, A. G., Crawford, M. A., Stevens, P. \& Denton, J. P. (1981). In Progress in Lipid Research, vol. 20, pp. 161-I67 [R. T. Holman, editor]. Oxford: Plenum Press.

World Health Organization (1982). Prevention of Coronary Heart Disease. Technical Report Series no. 678, Geneva: WHO. 